\title{
Teachers' teleworking job satisfaction during the COVID-19 pandemic in Europe
}

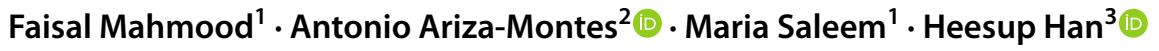 \\ Accepted: 30 September 2021 \\ (c) The Author(s), under exclusive licence to Springer Science+Business Media, LLC, part of Springer Nature 2021
}

\begin{abstract}
This research takes insights from the job demand resource model to examine the teleworking job satisfaction of teachers for the period of COVID-19 pandemic. This study evidenced that teachers' satisfaction with teleworking has been reduced as a consequence of the job demand increase. In contrast, access to adequate resources has allowed them to confront the challenges of teleworking, thus increasing their job satisfaction. The adverse effect of job demands on teleworking job satisfaction is buffered by job resources as teachers' required extra means to confront unexpected and increased job demands. The technological gap between younger and older teachers was uncovered.
\end{abstract}

Keywords Teleworking $\cdot$ Job satisfaction $\cdot$ Job demands $\cdot$ Job resources $\cdot$ JD-R model $\cdot$ COVID-19

\section{Introduction}

Technological improvements, the increased use of information technology, and new managerial perspectives concerning the importance of work rather than the place of work have enabled teleworking as an approach-to-work alternative to traditional styles (Tokarchuk et al., 2021; BelzuneguiEraso \& Erro-Garcés, 2020; Baruch, 2001; Davenport \& Pearlson, 1998). Nilles (1976) coined the term "teleworking" in 1970s. Kelly (1985) referred to teleworking as the "next workplace revolution" in the 1980s. The importance of teleworking remains ongoing among organisations, employers, employees, and the telecommunication industry (Handy

Heesup Han

heesup.han@gmail.com

Faisal Mahmood

faisalch62@gmail.com

Antonio Ariza-Montes

ariza@uloyola.es

Maria Saleem

mariyasaleem1989@gmail.com

1 The University of Lahore, Lahore, Pakistan

2 Social Matters Research Group, Universidad Loyola Andalucía, Sevilla, Spain

3 College of Hospitality and Tourism Management, Sejong University, Seoul, South Korea
\& Mokhtarian, 1996), and it has been suggested that virtual organisations are the new stage in organisational development (Chesbrough \& Teece, 1998).

Despite the great interest of academic scholars, managers, and organisations, there is no precise definition of teleworking, and there is no agreement concerning the term. It has been referred to distinctively as 'remote working', 'home working', 'telecommuting', and 'teleworking'; these terms have been used interchangeably in the literature (Tokarchuk et al., 2021). Notwithstanding these difficulties, teleworking is indicated as "an alternative work arrangement in which employees perform tasks elsewhere than is normally done in a primary or central workplace, for at least some portion of their work schedule, using electronic media to interact with others inside and outside the organization" (Gajendran \& Harrison, 2007, p. 1525). The present research will use the definition of teleworking suggested by Baruch (2001), which considers that "teleworking occurs when employees perform all or a substantial part of their work physically separated from the location of their employers using information technology for operations and communication" (p. 114). Other fundamental features of teleworking identified by the academic literature are the main role of people and technology (Pliskin, 1998), individuals' or people's readiness or willingness for teleworking (Baruch, 2001), technological access (i.e. the internet as a key catalyst in teleworking progress) (Tavares et al., 2020), and other essential factors, such as availability and the reduced cost of technological equipment, 
improvements in worldwide connectivity, and the quality of internet networks (Agarwal et al., 2020).

In an increasingly dynamic world and ever-changing organisational environment, people have been forced to adopt practices, methods, or processes that they have not experienced before. One of these especially serious situations was the unexpected appearance of the coronavirus outbreak in December 2019, which not only caused a vast number of casualties all around the world, but also challenged the whole world regarding disease control, working context, and other health, social and economic areas. In Europe, the pandemic became out of control in the first months of 2020 , creating absolute confusion that has affected mental health (Kanekar \& Sharma, 2020; Kumar \& Nayar, 2020). The reaction of European governments to the unexpected health crisis caused by COVID-19 was to recommend social isolation at first, and to impose home confinement shortly thereafter. Suddenly, a large portion of European employees turned from working to teleworking, which generated a growing interest in research on this matter (BelzuneguiEraso \& Erro-Garcés, 2020).

Likewise, the usual or common work routines were also curtly toppled by the COVID-19, and it promptly intensified the ongoing trends such as shifting of work to online or virtual settings. But a main dissimilarity is that working from home was usually dependent on the employees' priorities. In contrast to COVID-19 crisis, where optional work from home was forced to mandatory working from home without any priorities of the employees' (Kniffin et al., 2021a, 2021b). In the early outspread of the COVID-19, around half of the organizations, and $80 \%$ of their employees were working from home that substantially enhanced the remote working trends (Gartner, 2020). However, a number of employees were forced to work from home, and many confronted challenges because of some basic issues such as not having one's living space, living with family and others etc. (Kniffin et al., 2021a, 2021b). In line with these views, such as by Kniffin et al. (2021a, 2021b), teachers' were among those employees who were forced to work from home due to sudden suspension of in-person presence to suspend pandemic outspread. Similarly, Kniffin et al., 2021 bdocumented that working from home in lockdown or quarantine is distinctive than working from home before pandemic. Before pandemic, working from home was the combination of employers' and employees' preferences, and the level of trust between related parties as well. But mandatory working from home is distinctive and novel kind of working from home.

Without a doubt, teachers are one of the professional groups most affected by this new reality. The closure of schools, colleges, and universities has forced a radical change in the teaching model, moving to distance learning due to the provisional suspension of face-to-face teaching
(Unger \& Meiran, 2020). Practically from one day to the next, teachers, students and their families were forced to make an adaptation effort unknown until now. In the case of teachers, they had to radically change the way they do their work, moving to telework without being aware of the increase in job demands, or stopping thinking if they had the essential resources to cope with the drastic change involved in mandatory teaching from home.

On an individual level, not everyone had the same resources or was equally trained to face the challenge. Some teachers had previous experience in distance training, but others did not. Some of them handled new technologies well (possibly younger teachers), while others had more difficulty doing so (surely older teachers). According to King (2008), a successful telework plan should define the responsibilities of the employee and employer, the teleworker agreement, the hours of work, employee expenses (reimbursable and non-reimbursable), the procedures for tracking the maintenance and recovery of equipment, furniture and other assets, training requirements, and schedule, among other aspects. Therefore, it would be a process analysed and evaluated before its implementation. However, this description bears little resemblance to what happened during the first weeks of the pandemic. Suddenly, teachers were forced to engage in telework, although in reality it was more like working from home, closing their eyes and crossing their fingers, a kind of 'do what you can', without analysing or evaluating the consequences.

The scientific literature attributes both advantages and disadvantages to teleworking. Some advantages are the positive impact on teleworkers' job satisfaction, increased autonomy, and less work-family conflict (Gajendran \& Harrison, 2007), a positive link between telework and organisational commitment (Martin \& MacDonnell, 2012) or, in the organisational context, the effect of teleworking on energy savings (Hook et al., 2020). Equally, adverse effects of teleworking have also been reported, such as social isolation or coworker dissatisfaction (Golden et al., 2008; Golden, 2007). If, even with orderly implementation, the adverse effects of teleworking cannot be avoided, imagine what happened when all this change occurred in an improvised way.

This new reality generated by the appearance of COVID19 will necessarily have affected teachers' job satisfaction. During the pandemic, teachers (and many other employees) had to alternate the work methods from one day to next, in addition to sharing a home with their partner and children (this does not usually happen when teleworking is well planned). In this context, the job demands associated with unexpected telework have generated strains that have undoubtedly affected teachers' job satisfaction.

In addition, dedication of special issues on COVID-19 in various journals, and the resent calls for research also motivated us to conduct this study. For instance, it is imperative 
to examine the effect of COVID-19 on work related attitudes and behaviors (Rudolph \& Zacher, 2020); to investigate how employees of various professions and sectors suffered from COVID-19 pandemic (Gambrell, 2020); to explicate the how the pandemic crisis is managed by various organizations, institutes, and organizational leaders, and the impact of the policies or practices to manage the COVID-19 pandemic crisis on the workers of various age groups (Moench, 2020); to concentrate on the age-graded impacts such as overall increase in feelings and emotion capabilities with age, and to consider determinants (i.e., digital competency) and outcomes (i.e., occupational wellbeing) for different age group individuals during pandemic (i.e., younger vs. older) (Rudolph \& Zacher, 2020). And further, age as a moderating factor needs much attention as mandatory working from home may be distinctly experienced by individuals of different age group (Kniffin et al., 2021b). Accordingly, the key objective of the present study is to offer inclusive understandings for practitioners and academics by examining the job demands impact on teleworking job satisfaction by employing the job demands-resource model (Bakker \& Demerouti, 2007; Bakker et al., 2003), and investigating when job resources buffer the effect of job demands on teleworking job satisfaction by underpinning JD-R model as well as Hobfoll's (2001) COR theory. Last but not least, this research analyses the buffer effect of age on the JD-R model, since age can be a key factor in successfully tackling the 'improvised teleworking' that teachers had to react to.

Although some researchers have studied job satisfaction by employing JD-R model (e.g., Ghanayem et al., 2020; Yom, 2013), very few have focused on groups of teleworkers (e.g., Mansfield, 2018). Further, to our knowledge, none of them has tested this model with regard to teachers' satisfaction with teleworking and online training, and even less so when this situation has occurred in an improvised way due to social isolation measures taken by governments to minimize coronavirus spread. All this brings novelty and value to the present research.

\section{Literature and Hypotheses Development}

\section{Job Demands, Job Resources, and Teleworking Job Satisfaction}

In the last few decades, many studies have employed the JD-R model to examine the concepts of job demands and resources (Bakker \& Demerouti, 2007; Bakker et al., 2003). This model is important for workstations that need a holistic approach to wellbeing and work engagement (Berthelsen et al., 2018). It assimilates former representations of job stress and work engagement like Hackman and Oldham (1980) job characteristics model; Herzberg (1966) two-factor theory; and Karasek (1979) demand-control model. Remarkably, the JD-R model took many years of effort from pivotal effort of Demerouti et al. (2001), and much empirical research has been done to nurture and refine the current state of JD-R theory (Bakker et al., 2014). As per this theory, job-related burnout headways have two mechanisms: on the one hand, one that is linked to very stressful and unfavourable work settings where increased job demands induce tiredness and fatigue. The other is related to scarce or inadequate job resources that lead to disengagement (Demerouti et al., 2001).

Job demands refer to "physical, psychological, social, or organizational aspects of the job that require sustained physical and/or psychological (cognitive and emotional) effort or skills and are therefore associated with certain physiological and/or psychological costs" (Bakker \& Demerouti, 2007, p. 312). JD-R model considers that each job exhibits two large dimensions: job resources and demands. These factors are different among professions, so this model should be tested in various work contexts because each occupation carries its precise risk (Bakker \& Demerouti, 2007). Job demands can be turned into work stressors while achieving those demands needs many efforts from which employees have not been sufficiently enriched (Meijman et al., 1998). Further, job resources are considered "those physical, psychological, social, or organizational aspects of the job that are functional in accomplishing work goals, reduce job demands and the associated physiological and psychological costs or stimulate personal growth, learning, and development" (Bakker \& Demerouti, 2007, p. 312). Thus, these are essential to meet job strains (Bakker et al., 2003), and they are a means to attain or shelter other esteemed resources. This approach fits Hobfoll's (2001) COR theory, which explains human motivation focuses on maintaining and accumulating resources. People have the primary drive to protect, retain and obtain that which they consider valuable. According to Hobfoll et al. (2000), these resources can be categorised as objects (i.e. houses and furniture); conditions (i.e. work experience, marital status); personal characteristics (such resources that buffer stress); and energies (i.e. knowledge, money, time) (Gao et al., 2013). In addition, motivational prospective job resources may provide exceptional performance (Bakker \& Demerouti, 2007).

There seems to be a consistent stream of studies regarding job demands and job resources since last few decades by employing JD-R model (Zeijen et al., 2021; Cho et al., 2020; Lesener et al., 2019; Demerouti \& Bakker, 2011; Bakker \& Demerouti, 2007). For instance, it predicts teachers' job satisfaction (Han et al., 2020), employee wellbeing (Huang et al., 2019), teachers' occupational wellbeing (Dicke et al., 2018), stress and job burnout (Bakker \& Demerouti, 2017; Bakker et al., 2005), work engagement and connectedness (Hakanen et al., 2006; Lewig et al., 2007), work enjoyment 
and organisational commitment (Bakker et al., 2010). Generally, job demands are related to job strain, while job resources generate a motivational process that leads to job satisfaction, among other positive outcomes (Scanlan $\&$ Still, 2019). This model has also been used to examine sickness absenteeism (Clausen et al., 2012) and job performance (Bakker et al., 2008). Additionally, this model plays an important role in understanding and explaining employee wellbeing and job performance, and helps in making predictions about some employees' outcomes, such as their work engagement, health, burnout and motivation (Bakker \& Demerouti, 2007). While job demands are usually the essential determinant of consequences such as health concerns or complaints and fatigue (Hakanen et al., 2006), job resources are mostly considered significant factors of job engagement and motivation (Bakker et al., 2010).

Primarily, job demands require efforts and energies or resources, while job resources accomplish some core psychological necessities. For example, Bakker et al. (2004) employed JD-R model by examining the association of burnout, performance, and job characteristics, and noted that job demands significantly predicted burnout, while job resources anticipated extra role performance. Thus, increased job demands consume employees' mental and physical means, which eventually reduce their energies (Bakker \& Demerouti, 2007; Bakker et al., 2004). The JD-R model posits that every occupation exhibits its own particular labour characteristics. Specifically, teachers (who already bore many of the demands of the teaching profession) suddenly had to face new and severe job demands. All this was a consequence of the declaration of COVID-19 as a pandemic on March 11, 2020 and of the health decisions that days later were adopted to try to combat it. Among other job demands, teachers had to radically change the way they did their work, adapt to the use of technological tools that many of them were unaware of (Cisco Webex, Microsoft Teams, Blackboard Collaborate Ultra, Google Hangouts Meet, Zoom, etc.), learn to separate work time from personal time, and face fears and insecurities. All of this implied an increase in the hours of dedication to work, but also an increase in the burden from an emotional point of view.

These challenges had to be faced with limited and improvised resources, both of a physical nature (computers, photocopiers, computer networks, software, workspaces equipped for mandatory teleworking at home, etc.), as well as individual capacities (knowledge and experience in virtual teaching) and relational capacities (for example, the support of colleagues and/or superiors). Precisely, the ability to confront this radical change will be influenced by numerous conditioning factors, but age will undoubtedly be one of the most determining and significant. All of the above will have a direct effect on teacher satisfaction with teleworking. Previous studies carried out in the context of pre-pandemic normality have shown that teachers' workload is one of the job demands most intensely linked to their job satisfaction (Toropova et al., 2021). Likewise, Han et al. (2020) found that job demands comprising teaching demands, new challenges, and teaching-research conflicts diminished teachers' job satisfaction, while job resources containing social and administrative support and teaching resources improved teachers' job satisfaction.

Without a doubt, teleworking job satisfaction among teachers constitutes a significant research area. However, this objective is a real challenge since there is no consensus on what should be understood by job satisfaction (Aziri, 2011). The job satisfaction is widely discussed and investigated in the literature; for instance, as an arrangement of environmental, physiological, and psychological circumstances which causes an individual to fairly talk about his/her satisfaction with work (Hoppock, 1935), the approach individuals sense their work and its numerous facets (Spector, 1997), and degree to which individuals like or disinclination their jobs. Likewise, it is also referred to as individuals' feelings concerning their job or work (Armstrong, 2006). In the scientific literature, teachers' job satisfaction is conceptualised as their affective responses to their job (Skaalvik \& Skaalvik, 2017; Weiss, 2002). Job satisfaction has influential and in-depth effects for teachers as it is linked to desired work attitudes and job performance. Thus, the present research operationalised teleworking job satisfaction as the degree to which people feel contented or dissatisfied with their job by working from home or teleworking. JD-R model and COR theory are considered in this research to investigate how COVID-19 has adversely impacted the education sector, taking into account that educational institutions were closed and teachers were forced to work from home (Unger \& Meiran, 2020). The increase in job demands that this entailed should translate into lower job satisfaction, while the availability of resources should act in the opposite direction. Accordingly, we stated:

Hypothesis 1: Job demands are negatively related to teachers' teleworking job satisfaction.

Hypothesis 2: There is positive association between job resources and teachers' teleworking job satisfaction.

\section{The Moderation of Job Resources}

Bakker and Demerouti (2007) noted the interaction of job demands and job resources determines employee wellbeing as job resources buffer the impact of job demands on job stress (Bakker \& Demerouti, 2007; Bakker et al., 2003). This occurs because when workers have ample job resources, they can meet their day-to-day job demands in a better way. Consequently, as per Bakker and Demerouti (2018) job resources assist employees by confronting job demands. Further, job 
resources become more important and enhance the work dedication of employees when they must confront challenging job demands (Bakker \& Demerouti, 2007). In this sense, certain job resources like autonomy, social support, development opportunities, and performance view may mitigate the impact of job demands on strain and burnout (Yulita et al., 2020; Mayende \& Musenze, 2018; Xanthopoulou et al., 2007). Similarly, other job resources like flexibility in professional expertise alleviate the adverse effect of job demands (e.g. workload) on work engagement (Knight et al., 2017; Hakanen et al., 2005).

Further, job resources such as organisational support can improve employees' positive attitudes concerning their employment (Mayende \& Musenze, 2018; Blackmore \& Kuntz, 2011) in such a way that some job resources such as autonomy, social support, and promotion prospects alleviate the negative impact of job demands (e.g. role conflict or workload) on occupational outcomes, such as worker engagement involving abusive or hostile behaviours (Balducci et al., 2011). Regarding the educational environment, Bakker \& Demerouti, 2007focused on Finnish teachers and highlighted that job resources like appreciation, organisational climate, and supervisory support assisted teachers in confronting demanding communication with students. Therefore, previous literature concerning JD-R model has explicitly indicated the interaction of job demands and resources may have an intensifier effect on work-related employee outcomes such as wellbeing, stress, work engagement, or hostility behaviours (Mayende \& Musenze, 2018; Balducci et al., 2011; Bakker \& Demerouti, 2007; Hakanen et al., 2005). The present research takes insights from the JD-R model to explain the buffering impact of job resources on the effect of job demands among education sector employees (e.g., increased workload due to swift shift from in-person teaching to teleworking because of COVID-19) on their teleworking job satisfaction. Thus, it is hypothesized that:

Hypothesis 3: The adverse impact of job demands on teachers' teleworking job satisfaction is buffered by job resources.

\section{The Moderation of Age}

Research on ageing and work is explicitly gaining momentum. However, workforce ageing is still mostly considered in a negative light by practitioners, and thus concentrates on conflicts and difficulties, rather than opportunities and potential (Hertel \& Zacher, 2018) because of stereotypes about age in the workplace. In COVID-19 pandemic older employees were extremely at risk of getting infected and dying, and thus they deserve considerable attention (Kniffin et al., 2021a, 2021b). Whereas, the adoption and success of teleworking depends on some key factors. Torten et al. (2016) pointed out the employees' readiness and openness for such work engagement, as well as the organisation's desire and openness to take the edge in this sense, have suitable infrastructure based on communication and information technology.

Although teleworking provides clear benefits for both the company and the workers (Beauregard et al., 2019; Turetken et al., 2010), the adoption of teleworking is much slower, as anticipated due to several aspects (Pyöriä, 2011). These factors may be the organisational culture, employee priorities concerning work-life balance, or regulatory issues, among others (Calvasina et al., 2012). However, the fast progress in technology and communications in the last few years has not only promoted teleworking, but also facilitated employees' work apart from their offices (Hook et al., 2020). Similarly, teleworking has become even more essential with an increase in technology use (Groen et al., 2018). Further, teleworking has proven to be an essential tool for employees and employers to continue their everyday job responsibilities in challenging period that began at the start of the pandemic. COVID-19 has severely influenced almost every economic industry. Education has certainly been one of the most affected. Elementary schools, colleges, and universities were shut down, in-person training was shifted to distance learning education, such as online classes (Unger \& Meiran, 2020), and educational institutes made immense efforts to find suitable ways to continue students' studies, such as through online teaching. However, educational institutions were confronting various problems due to the unavailability and unfamiliarity of their employees and students with the latest technology, and much emphasis was given to teachers' attitudes toward the use of information technology. Moreover, teachers' age was important in this regard. For instance, older teachers may perceive increased job demands derived from teleworking in contrast to younger teachers, and this fact may reduce their teleworking job satisfaction. Many workers around the world are redefining their work patterns, but the adaptation effort this implies is greater among older employees, as they are reluctant to learn and adopt new technologies (Robbins \& Judge, 2013).

Existing studies also stress that job demands distinctively influence older employees' job satisfaction in comparison to younger employees (Scheibe et al., 2015). The younger generation is much proficient in remote working, and with the worldwide move towards working from home to limit the outspread of COVID-19 can further provide them flexibility for distant working (Rudolph \& Zacher, 2020). Surely, this situation occurs because younger people chase forward-looking objectives, concentrating their energies on learning and personal progress. However, older workers focus on present objectives and need more resources and related knowledge to accomplish unusual tasks and to buffer age-associated 
deterioration (Hertel \& Zacher, 2018). Consequently, it is a great challenge for them to manage telework-related activities since this greater or lesser capacity will necessarily impact their work satisfaction. The present research argues that older teachers will have more problems confronting teleworking than younger teachers. Accordingly, we hypothesised the following regarding the moderating effect of age:

Hypothesis 4: Older teachers perceive higher job demands from teleworking, leading to lower work satisfaction than among young teachers.

Hypothesis 5: Older teachers need greater job resources to face teleworking, leading to higher work satisfaction than young teachers if they are provided with them.

According to the previous arguments, the proposed research model is drawn in Fig. 1.

\section{Methods}

\section{Data Collection and Sample}

This research is based on Eurofound's COVID-19 Working and Living survey. Eurofound is a European Union Agency that provide knowledge in the area of social, employment and work-related policies. Three rounds of this survey have been carried out to date: (a) Round 1: Launched on 9 April 2020 when most Member States were in their first lockdown; (b) Round 2: July 2020 when economies and societies were gradually reopening; and (c) Round 3: March 2021, almost a year on, as countries were still dealing with various levels of lockdown. This research was carried out with a sub-sample extracted of the second round, where respondents were asked about the use of teleworking during the COVID-19 crisis. The fieldwork was performed via uncontrolled convenience sampling throughout June and July 2020 in the European Union's 27 countries. The total number of surveys collected was 24,123 . For further information on methodology, please see https://www. eurofound.europa.eu/data/covid-19. In the present study, a subsample of 523 employees from the education sector, probably the most impacted by telework during the pandemic, was extracted. These teachers had not teleworked before the pandemic, and suddenly were forced to do so as a result of COVID-19. Table 1 shows the main respondents' characteristics.

Table 1 Socio-demographic factors

\begin{tabular}{ll}
\hline Variables & $\%$ \\
\hline Gender & \\
a) Female & $88.3 \%$ \\
b) Male & $11.7 \%$ \\
Age group & \\
a) $=$ < 45 years & $34.2 \%$ \\
b) > 45 years & $65.8 \%$ \\
Spouse or partner in household & \\
a) Yes & $67.9 \%$ \\
b) No & $32.1 \%$ \\
Children living at home & \\
a) Yes & $45.5 \%$ \\
b) No & $54.5 \%$ \\
Education level completed & \\
a) Tertiary & $92.1 \%$ \\
b) Secondary & $7.9 \%$ \\
Employment contract in main job & \\
a) Contract of unlimited duration & $81.3 \%$ \\
b) Contract of limited duration & $16.3 \%$ \\
c) Others & $2.4 \%$ \\
General health & \\
a) Very good & $23.7 \%$ \\
b) Good & $46.8 \%$ \\
c) Fair & $25.8 \%$ \\
d) Bad & $3.6 \%$ \\
\hline &
\end{tabular}

Fig. 1 Hypothesised model

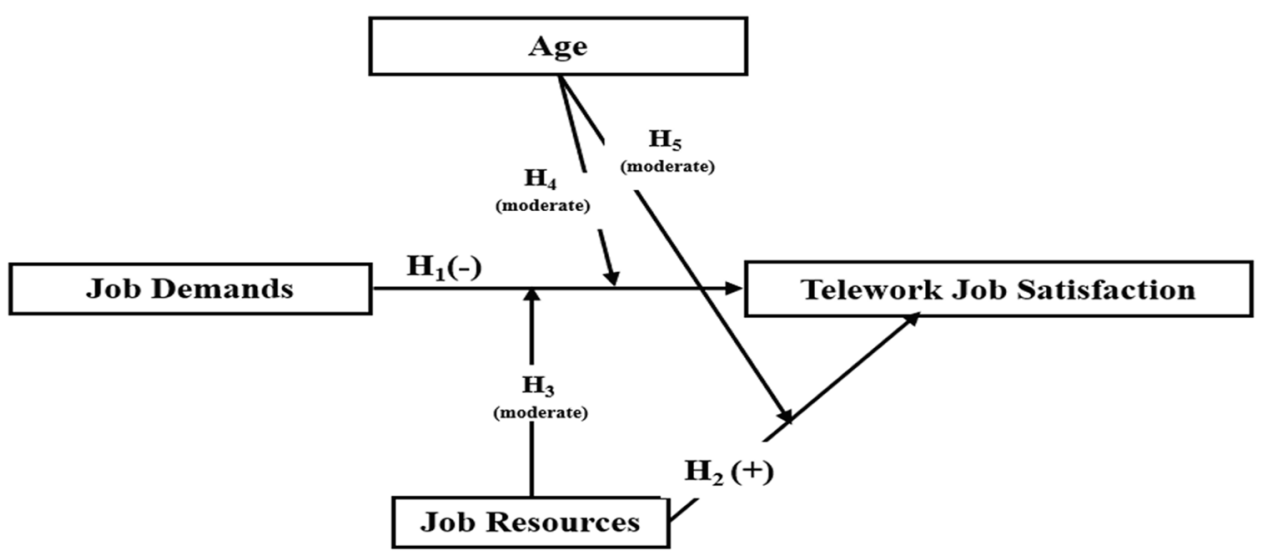




\section{Measurements}

The dependent variable in this research is teachers' job satisfaction with telework which is operationalized as the degree to which people feel contented or dissatisfied with their job by mandatory working from home. Accordingly, teachers that participated in Eurofound's COVID-19 Working and Living survey answered the following three items related to their teleworking job satisfaction: I am satisfied with the amount of work I have managed to do; I am satisfied with the quality of my work; and I am satisfied with my experience of working from home. Teachers pointed out their level of agreement on a 5-point Likert scale (1: strongly agree; 5: strongly disagree).

Job demands and job resources are the explanatory variables of the JD-R model. The items and codes of each group were measured as follows. On the one hand, Job demands were operationalized in terms of workload and emotional demands as suggested by Bakker and Demerouti (2007) due to the rapid change from in-person presence to mandatory work from home through the following items: D1. During the COVID-19 pandemic, the amount of work you managed to do... (5: increased a lot; 1 : decreased a lot); D2. You have the feeling you are doing useful work (1: always; 5 : never); D3. You feel physically exhausted at the end of the workday (1: always; 5: never); D4. You feel emotionally drained by work (1: always; 5: never); D5. You feel isolated when working (1: always; 5: never); D6. You have enough time to get the job done (1: always; 5: never). On the other hand, the job resources were operationalized in the view of social support by following Balducci et al. (2011) and availability of personnel resources measured by using following items from Eurofound's COVID-19 Working and Living survey: $\mathrm{R} 1$. With the equipment I have at home I could do my work properly (1: strongly agree; 5 . strongly disagree); R2. My employer provides all the equipment I need to work from home (1: strongly agree; 5: strongly disagree); R3. Your colleagues or peers help and support you (1: always; 5 : never); R4. Your manager helps and supports you (1: always; 5: never).

\section{Analysis Strategy}

The present research employed contemporary analysis techniques. For instance, we conducted preliminary data analysis to test for normality, outliers, accuracy, and missing values in the dataset. After confirming the initial suitability of the data, we performed confirmatory factor analysis (CFA) in AMOS to examine model fitness and to assess the validity of the underlying constructs. CFA can be employed for various purposes, for instance, psychometric evaluation, construct validity, method effects detections, and the measurement model evaluation. CFA is an essential technique for the estimation of scale reliability and construct validity (Brown \& Moore, 2012). In addition, CFA is frequently employed and explicated the importance of the CFA. For instance, Mueller and Hancock (2001) documented that CFA is a quantitative data analysis technique that is linked with structural equation modelling (SEM) methods. It permits the estimation of fit between observed data and theoretically grounded deductive models that stipulates the hypothesized casual association of latent factors and observed variables. In contrast, exploratory factor analysis (EFA) is suitable if the researcher intents to explore ungrounded links suggested by the data. One of the key benefit of CFA is the capability to estimate the excellence of data-model fitness by using fit indices i.e., Standardized Root Mean-Square Residual, Root Mean-Square Error of Approximation, Comparative Fit Index (Bentler, 1990; Hu \& Bentler, 1999; Mueller \& Hancock, 2001).

Existing literature extensively used the CFA for multiple purposes. For instance, to examine the validity of the scales and internal structure (Arpaci \& Esgi, 2020), and to test the model fitness (Sun et al., 2020; Wang et al., 2017). Accordingly, the present research conducted the CFA test to examine model fitness and to assess the validity and reliability of the underlying constructs. We employed some frequently used indices for the model's fitness: chi-square goodness of fit, comparative fit index (CFI), root mean square error approximation (RMSEA), and Tucker-Lewis index (TLI). In addition, constructs validity was measured by utilizing average variance extracted (AVE) and maximum shared variance (MSV), while reliability was estimated via composite reliability and Cronbach's alpha. Thus, after establishing model fitness, validity and reliability of the constructs, structural equation modelling was employed by using AMOS for hypothesis development.

\section{Results}

Table 2 shows that validity and reliability of the scales are in the satisfactory range. To establish the validity of the constructs, AVE should be greater than 0.50, and MSV should below AVE. Further, to establish the reliability of the scales, the values for the Cronbach's alpha and composite reliability

Table 2 Scale validity and reliability

\begin{tabular}{llllll}
\hline Variables & Items & Alpha & AVE & MSV & CR \\
\hline Job Demands & 6 & 0.70 & 0.62 & 0.36 & 0.80 \\
Job Resources & 4 & 0.66 & 0.59 & 0.41 & 0.77 \\
Job Satisfaction & 3 & 0.75 & 0.66 & 0.21 & 0.86 \\
\hline
\end{tabular}

$\mathrm{CR}$ is the composite reliability, AVE presents average variance extracted, and MSV is a maximum shared variance 
must be above 0.60 and 0.70 , respectively (Hair et al., 2013). Thus, the present research found that the average variance extracted values for job demands, job resources, and job satisfaction are above $0.70,0.66$, and 0.75 , respectively; the maximum shared variance is also less than the average variance extracted values. Similarly, we found that composite reliability and Cronbach's alpha were higher than the threshold level to account for reliability. Thus, the validity and reliability of the constructs are not a threat for this research.

Descriptive statistics and correlations results are stated in Table 3. The mean value for job demands is 3.11 , which is higher than that for job resources and job satisfaction, which are 2.76 and 2.29 , respectively.

This is due to the increased job demands during the COVID-19 period and lower job resources. This situation may be because on a scale of 1 to 5 , the teleworking job satisfaction of teachers is only 2.29. Further, the mean value for age is 1.66 , which is estimated by coding the respondents' ages into two categories: younger teachers (coded 1 if age is less than or equal to 45 years) and older teachers (coded 2 if age is greater than 45 years). Although working life in Europe may fluctuate between different countries, it is very common for it to range between the ages of 25 and 65. Consequently, many teachers are in the middle of their professional careers at age 45 , which prompted us to use this criterion as a cut-off point. Thus, the mean value of 1.66 represents older teachers than younger ones in the dataset. Moreover, the standard deviation values for all variables are not too high or too low. The data normality was tested by skewness and kurtosis, and the values were in the satisfactory range \pm 1.96 (Tabachnick et al., 2007).

Moreover, the bivariate correlation coefficients are reported in Table 3 and are in the supposed directions. For example, we found a statistically significant negative correlation between job demands and job resources $(-0.28$, $\mathrm{p}<0.01)$. Further, a negative and significant correlation between job demands and job satisfaction $(-0.18, \mathrm{p}<0.01)$, and a positive and significant correlation between job resources and job satisfaction, were noted $(0.29, \mathrm{p}<0.01)$. Thus, our results are free from multicollinearity problems, and our data are suitable for further analysis.

\section{Measurement Model}

CFA was conducted to test for the model's fitness. These values for model fitness indicators were in the satisfactory range as defined by Hair et al. (2013). For example, CMIN $=1.858$, $\mathrm{RMSEA}=0.089, \mathrm{RMR}=0.051, \mathrm{TLI}=0.94, \mathrm{CFI}=1.00$.

\section{Hypotheses Development}

After establishing the constructs' validity, reliability, summary statistics, bivariate correlations, and model fitness, hypothesis development was performed. The results are reported in Table 4 and Figs. 2 and 3. In Hypothesis 1 , the adverse impact of job demands on teleworking job satisfaction was stated. The results found a statistically significant negative effect of job demands on teleworking
Table 3 Descriptive statistics and correlation

Table 4 Summary of the direct and moderating effects

\begin{tabular}{lllllllll}
\hline & Mean & SD & Skew & Kurt & 1 & 2 & 3 & 4 \\
\hline 1. Job Demands & 3.11 & 0.57 & -0.30 & 0.36 & 1 & & & \\
2. Job Resources & 2.76 & 0.77 & 0.09 & -0.44 & $-0.28^{* *}$ & 1 & & \\
3. Job Satisfaction & 2.29 & 0.82 & 0.62 & 0.18 & $-0.18^{* *}$ & $0.29^{* *}$ & 1 & \\
4. Age & 1.45 & 0.50 & 0.22 & -1.95 & -0.01 & -0.02 & -0.04 & 1 \\
\hline
\end{tabular}

$* * \mathrm{p}<0.01, \mathrm{SD}=$ Standard deviation, Skew $=$ Skewness, and Kurt $=$ Kurtosis

\begin{tabular}{lllll}
\hline & Estimate & C. Ratio & $p$ value & Remarks \\
\hline Direct Effects & & & & \\
Job Demands $\rightarrow$ Job Satisfaction & $-0.10^{*}$ & -2.30 & 0.020 & Supported (H1) \\
Job Resources $\rightarrow$ Job Satisfaction & $0.26^{* *}$ & 6.62 & 0.000 & Supported (H2) \\
Moderation of Job Resource & & & & \\
Job Demands* Job Resources $\rightarrow$ Job Satisfaction & $-0.04^{*}$ & -2.35 & 0.009 & Supported (H3) \\
Moderation of Age $($ Youngers vs. Older $)$ & & & & \\
Job Demands*Older Age $\rightarrow$ Job Satisfaction & $-0.14^{*}$ & -1.99 & 0.023 & Supported (H4) \\
Job Demands*Younger Age $\rightarrow$ Job Satisfaction & $-0.09^{* *}$ & -2.05 & 0.039 & \\
Job Resources*Older Age $\rightarrow$ Job Satisfaction & $0.30^{* *}$ & 4.75 & 0.000 & Supported (H5) \\
Job Resources*Younger Age $\rightarrow$ Job Satisfaction & $0.27^{* *}$ & 3.21 & 0.000 & \\
\hline
\end{tabular}

$* p<0.05, * * p<0.01$, C. Ratio $=$ critical ratio 


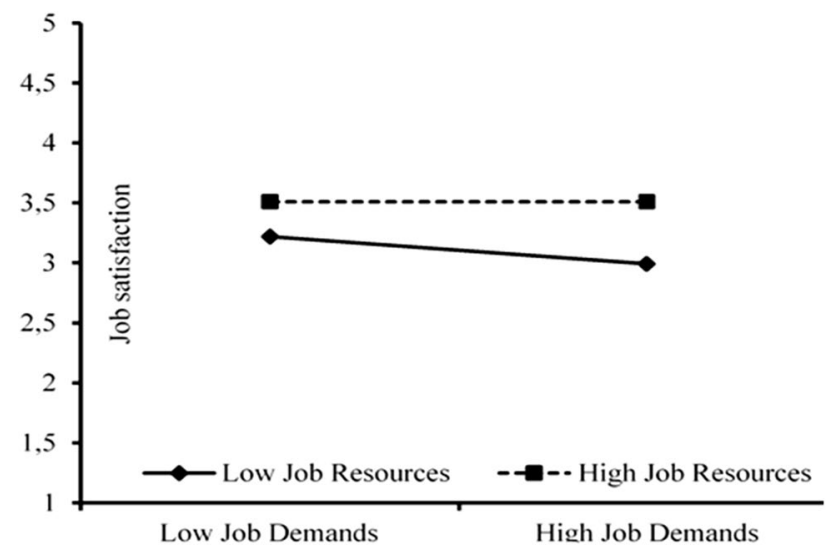

Fig. 2 Moderation of job resources

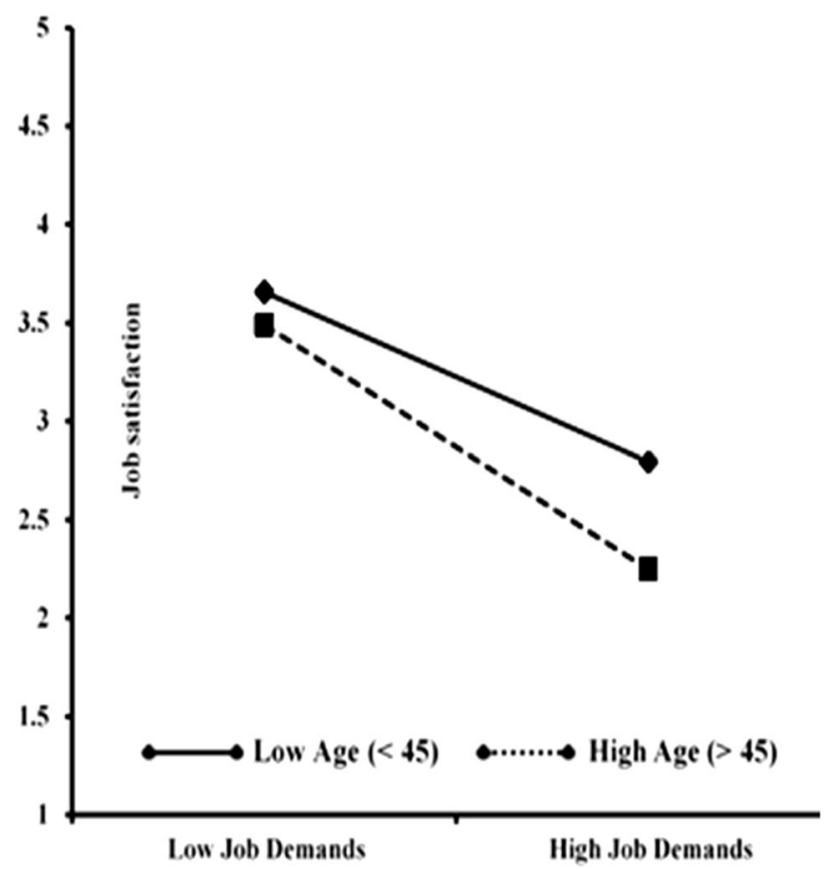

Fig. 3 Moderation of age on the direct effect of job demands on job satisfaction

job satisfaction $(-0.10, \mathrm{p}<0.020)$. Accordingly, by keeping all other things constant, with a one-unit increase in job demands, teachers' teleworking job satisfaction decreases by 0.10 units. Thus, Hypothesis 1 of the present study is supported.

Hypothesis 2 proposed a positive association of teleworking job satisfaction and job resources. We found job resources are positively and significantly related to teleworking job satisfaction $(0.26, \mathrm{p}<0.000)$. Hence, with a one-unit increase in job resources, teachers' teleworking job satisfaction increases by 0.26 units by keeping all other things constant. Therefore, Hypothesis 2 is supported as well. In Hypothesis 3, we stated that job resources buffer the negative influence of job demands on teleworking job satisfaction in such a way that the adverse consequences are lowered when job resources are high than when they are low. Our results support this statement. Consequently, the moderating effect of job resources buffers the direct effect of labour demands on teachers' teleworking job satisfaction: -0.04 (with moderation) instead of -0.10 (without moderation). To better understand these results, we plotted this contingency effect in Fig. 2, which shows the impact of job demands on teachers' teleworking job satisfaction is contingent on the level of job resources. As we can check in this figure, teachers' teleworking job satisfaction is higher in case job resources are available, both in the context of low and high job demands.

We also investigated the contingency effect of age in a double sense. On the one hand, Hypothesis 4 pointed out that older teachers perceive higher job demands from teleworking, leading to lower work satisfaction than younger teachers. Accordingly, the teleworking job satisfaction of older teachers fell further $(-0.14, \mathrm{p}<0.023)$ than that of younger teachers $(-0.09, \mathrm{p}<0.039)$ due to increased job demands. These results are statistically significant. The moderation effect of age on the influence of job demands on teachers' teleworking job satisfaction is also plotted in Fig. 3. This figure shows how job satisfaction decreases as job demands rise, but this effect is less severe among younger teachers compared to older teachers. Thus, Hypothesis 4 is supported.

On the other hand, we tested the contingency effect of age on the relationship among job resources and teleworking job satisfaction. Hypothesis 5 stated that older teachers need greater job resources to deal with teleworking in such a way that if they were to have these resources, they could gain higher work satisfaction than younger teachers. The research model found that the teleworking job satisfaction of older teachers improved by enhancing job resources $(0.30 \mathrm{p}<0.000)$ compared to that of younger teachers $(0.27$, $\mathrm{p}<0.000$ ). This relationship is statistically significant. The moderating effect of older and younger teachers on the direct influence of job resources on their teleworking job satisfaction is plotted in Fig. 4. As shown in this figure, when high job resources were provided to the older teachers, their teleworking job satisfaction increases to a greater extent than that of younger teachers, as indicated by the slope of the two lines. Thus, Hypothesis 5 is also supported.

\section{Discussion and Conclusion}

In March 2020, the reality as we knew it in Europe completely changed. Citizens were forced to adapt to a new situation, both in their personal lives and in the professional arena. Each person and each worker lived those months 


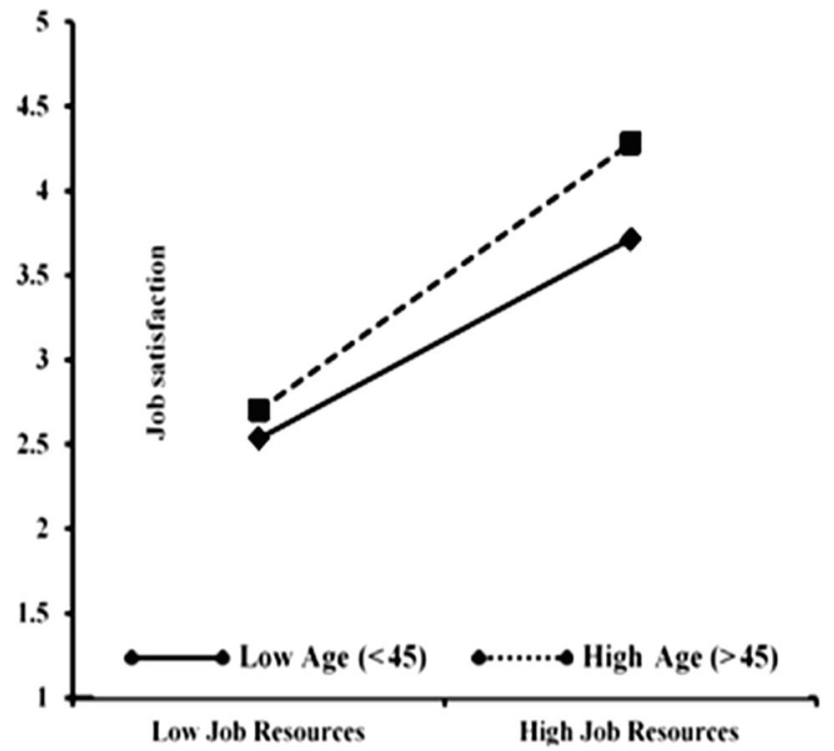

Fig. 4 Moderation of age on the direct effect of job resources on job satisfaction

in a particular way. One of the professional groups most affected by the coronavirus crisis is undoubtedly teachers. Unexpectedly, these professionals became forced to work (i.e. to teach) in a different way, without anyone having specifically prevented or trained them for it. From one day to the next, job demands increased, while available resources depended on exogenous factors such as age, education, interest in new technologies, and the type of home or structure of the family unit, among others. All this will necessarily affect teachers' level of satisfaction with a new reality where telework prevails.

This research aims to examine the relationship among job demands and teleworking job satisfaction by underpinning JD-R model of Bakker and Demerouti (2007), as well as the moderating effect of age on this model. The use of structural equation modelling among a sample of 523 teachers in Europe concluded that the coronavirus impelled teachers to telework, increasing their job demands in aspects such as doing useful work, feeling physically exhausted at the end of the workday, or the amount of work they managed to do during the COVID-19 pandemic. Although the change to online learning and training methods was made in a forced way by confinement and with the aim of preserving the health of teachers and students, the results of this research indicate that teachers' satisfaction with teleworking was reduced due to the increase in job demands.

Our results are in-lined with the JD-R model and with the existing literature. For instance, in consistent with the JD-R model, job demands require efforts and energies or resources, and thus adversely affect employees' physical and mental health (Bakker \& Demerouti, 2007). Likewise,
Meijman et al. (1998) noted job demands can be turned into job stressors or are supposed to be undesirable when achieving those demands, which requires much exertion from which employees have not been sufficiently enriched. Scanlan and Still (2019) also noticed job demands, work-home interference, and shift work were related to exhaustion. Hakanen et al. (2006) argued that job demands are usually the essential determinant of health concerns or complaints and fatigue. In this sense, Bakker et al. (2003) tested whether increased job demands or work overload consume employees' physical and mental resources, which eventually weaken their energies. In a context closer to this research, Han et al. (2020) pointed out that teachers' job satisfaction was influenced by job demands, comprising high teaching demands, new challenges in teaching methods, and teaching-research conflicts. Further, Toropova et al. (2021) in Sweden highlighted a heavy relationship between working circumstances and teachers' job satisfaction. Certainly, cooperation with other colleagues, workload and teachers' views of student discipline in school found to be main components of teachers' job satisfaction.

We also found that job resources positively impact teachers' teleworking job satisfaction. Without doubt, the swift and unexpected change from an in-person mode to distance learning strained these professionals. However, this research tested whether access to adequate resources (such as having the equipment that teachers need to do their work properly, or counting on the support of managers and/or colleagues) allowed them to confront the challenge of teleworking, thus increasing their job satisfaction along with it. The results of this research are consistent with the existing literature like JD-R model (Bakker \& Demerouti, 2007; Bakker et al., 2003), which specifies that job resources are essential to confront job demands and significant in their specific privileges, as they offer the means to attain or protect other esteemed resources (Bakker et al., 2003). Moreover, our results support COR theory, which asserts that the main human motivation is focused on protecting, maintaining and accumulating resources (Hobfoll et al., 2000). Thus, job resources may improve teachers' teleworking job satisfaction because they need such resources (e.g. work experience, personal characteristics, energies, etc.) to confront the requirements and demands of their jobs (Gao et al., 2013; Bakker \& Demerouti, 2007; Hobfoll et al., 2000). According to Miao et al. (2017), job resources positively impact one's job satisfaction, as they provide several social, psychological, and physical resources to employees.

In addition, we investigated the interaction effect of job demands and job resources on teachers' teleworking job satisfaction. Our research model verified that job resources shield the influence of job demands on teleworking job satisfaction. As teachers require increased resources to confront with unexpected and increased job demands, the adverse 
impact of job demands on teachers' teleworking job satisfaction is lessened when job resources are higher, versus when they are lower. Therefore, our findings validate a key perception of the JD-R model, which states that interaction effect of job demands and job resources determines employee wellbeing, since job resources shield the impact of job demands on stress (Bakker \& Demerouti, 2007). The obtained results are also consistent with other studies, such as those that confirm that job resources give employees the means to confront job strains (Bakker \& Demerouti, 2018), job resources become important and increase employees' work dedication when they confront challenging job demands (Bakker \& Demerouti, 2007), and they mitigate the negative effect of job demands on occupational consequences such as worker engagement (Balducci et al., 2011), and job resources improve employees' positive attitudes concerning their employment (Mayende \& Musenze, 2018).

Although our findings are in-lined with the past literature that uses COR theory as a frame of reference and JD-R model as a practical application, to our knowledge, none of these studies has evaluated the satisfaction experienced by teachers with teleworking and distance training. Therein lies precisely the novelty of this research, an interest that is reinforced by considering two additional key elements. On the one hand, this analysis was carried out in a radically new and unexplored context in the midst of a global health crisis that has shaken the foundations of the world we have known until now. On the other hand, the process of adaptation to teleworking was not orderly and planned, but rather quite the opposite. It consisted of a 'do what you can' attitude due to the speed with which the virus spread, and the consequent confinement measures adopted urgently by affected countries.

Finally, to deepen this novel scenario, we posited that the technological gap (in terms incorporating and using new technologies) between young and old people would somehow affect the running of the JD-R model, conditioning the ability to resist and the effects on teachers' job satisfaction. In this way, the structural equation model confirmed that older teachers perceive higher job demands derived from work and forced teaching from home. As a consequence, we concluded that the teleworking job satisfaction of older teachers is worse than that of younger teachers. At the same time, older teachers need greater job resources to face job demands derived from teleworking, in such a way that if employers provide technical equipment to work from home or teachers have the support of supervisors and/or peers, this leads to higher work satisfaction compared to younger teachers. These findings are as per those obtained in Scheibe et al. (2015). These authors used a sample of healthcare employees throughout Germany to confirm the contingency of age in the job demands-job satisfaction relationship, such that the link is stronger among older workers than among young workers. Nonetheless, the present research calls for more investigation to verify the results of this study.

Some interesting implications are offered by this research, both at a practical and a theoretical level. Concerning the theoretical sphere, we highlight the following issues. First, many academic studies have explored the influence of job demands on employees' workplace behaviours and consequences, such as job burnout (Bakker et al., 2005), organisational commitment (Bakker et al., 2010), and connectedness (Lewig et al., 2007). However, this is among the few early studies to examine the effect of increased job demands due to COVID-19 on the employees' teleworking job satisfaction in the education sector. Second, from a theoretical viewpoint, we contributed by analysing the influence of job resources on teachers' teleworking job satisfaction, a research question that has not been investigated until now in these very special circumstances of health crises. Third, the present research extended the JD-R model literature by employing this perspective with regard to teachers' teleworking job satisfaction. In this sense, we confirmed that the basic ideologies of the JD-R model were also applicable to the telework situation, generated as a consequence of the pandemic declared in 2020. Finally, we advanced scientific knowledge by examining the role of age in relation to this model, finding a different behaviour between older teachers compared to younger teachers.

Concerning the practical implications of this research, the health crisis suffered in Europe since 2020 should make us reflect on organisations' capacity to face the challenges of an increasingly uncertain and dynamic environment. In this sense, human resources managers should implement (and allocate an appropriate budget for) training policies aimed at helping employees acquire the necessary competencies to face unusual and unexpected changes in their job demands. Specifically, teachers should develop skills and learn knowledge in the use of online training tools. The aim is to provide teachers with resources that allow them to adapt more efficiently to teleworking job demands in the event of new confinement. In this sense, future recruitment processes should assess candidates' basic knowledge and expertise in information technology.

\section{Limitations and Future Directions}

Despite its numerous contributions, this research is not free of limitations that could provide potential prospects for upcoming research. First, the data used in this research were collected in very special circumstances. Therefore, future studies should replicate these analyses in normal work settings. Longitudinal studies would also be welcome in this regard. Second, this research is limited to the education sector in Europe. Future studies must consider other sectors 
and countries to better understand the underlying model of the present research. Finally, in future research we will try to analyse the influence of the school model: e.g., rural vs. urban or public vs. private.

Data availability The dataset used in this research is available under request to the European Foundation for the Improvement of Living and Working Conditions-Eurofound.

\section{Declarations}

Ethical statement Because of the observational nature of the study, and in the absence of any involvement of therapeutic medication, no formal approval of the Institutional Review Board of the local Ethics Committee was required. Nonetheless, all subjects were informed about the study and participation was fully on a voluntary basis. Participants were ensured of confidentiality and anonymity of the information associated with the surveys. The study was conducted according to the guidelines of the Declaration of Helsinki.

Informed consent Informed consent has been obtained from all subjects involved in this study to publish this paper.

Conflicts of interest The authors declare no conflict of interest.

\section{References}

Agarwal, S., Ramadani, V., Gerguri-Rashiti, S., Agrawal, V., \& Dixit, J. K. (2020). Inclusivity of entrepreneurship education on entrepreneurial attitude among young community: Evidence from India. Journal of Enterprising Communities: People and Places in the Global Economy, 14(2), 299-319.

Arpaci, I., \& Esgi, N. (2020). Psychometric properties of the Turkish version of the smartphone addiction inventory (SPAI). Current Psychology, 39(6), 2246-2251.

Aziri, B. (2011). Job satisfaction: A literature review. Management Research \& Practice, 3(4), 77-86.

Bakker, A. B., \& Demerouti, E. (2007). The job demands-resources model: State of the art. Journal of Managerial Psychology, 22(3), 309-328.

Bakker, A. B., \& Demerouti, E. (2017). Job demands-resources theory: Taking stock and looking forward. Journal of Occupational Health Psychology, 22(3), 273-285.

Bakker, A. B., \& Demerouti, E. (2018). Multiple levels in job demandsresources theory: Implications for employee well-being and performance. In E. Diener, S. Oishi, \& L. Tay (Eds.), Handbook of well-being. Noba Scholar.

Bakker, A., Demerouti, E., \& Schaufeli, W. (2003). Dual processes at work in a call Centre: An application of the job demandsresources model. European Journal of Work and Organizational Psychology, 12(4), 393-417.

Bakker, A. B., Demerouti, E., \& Verbeke, W. (2004). Using the job demands-resources model to predict burnout and performance. Human Resource Management: Published in Cooperation with the School of Business Administration, The University of Michigan and in alliance with the Society of Human Resources Management, 43(1), 83-104.

Bakker, A. B., Demerouti, E., \& Euwema, M. C. (2005). Job resources buffer the impact of job demands on burnout. Journal of Occupational Health Psychology, 10(2), 170-180.
Bakker, A. B., Hakanen, J. J., Demerouti, E., \& Xanthopoulou, D. (2007). Job resources boost work engagement, particularly when job demands are high. Journal of Educational Psychology, 99(2), 274-284.

Bakker, A. B., Schaufeli, W. B., Leiter, M. P., \& Taris, T. W. (2008). Work engagement: An emerging concept in occupational health psychology. Work \& Stress, 22(3), 187-200.

Bakker, A. B., Van Veldhoven, M., \& Xanthopoulou, D. (2010). Beyond the demand-control model. Journal of Personnel Psychology, 9(1), 3-16.

Bakker, A. B., Demerouti, E., \& Sanz-Vergel, A. I. (2014). Burnout and work engagement: The JD-R approach. Annual Review of Organizational Psychology and Organizational Behavior, 389-411.

Balducci, C., Schaufeli, W. B., \& Fraccaroli, F. (2011). The job demands-resources model and counterproductive work behaviour: The role of job-related affect. European Journal of Work and Organizational Psychology, 20(4), 467-496.

Baruch, Y. (2001). The status of research on teleworking and an agenda for future research. International Journal of Management Reviews, 3(2), 113-129.

Beauregard, T. A., Basile, K. A., \& Canónico, E. (2019). Telework: Outcomes and facilitators for employees. In R. N. Landers (Ed.), The Cambridge handbook of technology and employee behavior (pp. 511-543). Cambridge University Press.

Belzunegui-Eraso, A., \& Erro-Garcés, A. (2020). Teleworking in the context of the Covid-19 crisis. Sustainability, 12(9), 3662.

Bentler, P. M. (1990). Comparative fit indexes in structural models. Psychological Bulletin, 107(2), 238-246.

Berthelsen, H., Hakanen, J. J., \& Westerlund, H. (2018). Copenhagen psychosocial questionnaire-a validation study using the job demand-resources model. PLoS ONE, 13(4), 1-15.

Blackmore, C., \& Kuntz, J. R. (2011). Antecedents of job insecurity in restructuring organisations: An empirical investigation. New Zealand Journal of Psychology, 40(3), 7-18.

Brown, T. A., \& Moore, M. T. (2012). Confirmatory factor analysis. Handbook of Structural Equation Modeling, 361-379.

Calvasina, G. E., Calvasina, R. V., \& Calvasina, E. J. (2012). The virtual office: HRM legal, policy, and practice issues. Business Studies Journal, 4(2), 37-46.

Chesbrough, H. W., \& Teece, D. J. (1998). When is virtual virtuous? Organizing for innovation. The strategic Management of Intellectual Capital, 27.

Cho, S., Noh, H., Yang, E., Lee, J., Lee, N., Schaufeli, W. B., \& Lee, S. M. (2020). Examining the job demands-resources model in a sample of Korean correctional officers. Current Psychology, 39(5), 1521-1534.

Clausen, T., Nielsen, K., Carneiro, I. G., \& Borg, V. (2012). Job demands, job resources and long-term sickness absence in the Danish eldercare services: A prospective analysis of registerbased outcomes. Journal of Advanced Nursing, 68(1), 127-136.

Davenport, T. H., \& Pearlson, K. (1998). Two cheers for the virtual office. MIT Sloan Management Review, 39(4), 51-65.

Demerouti, E., \& Bakker, A. B. (2011). The job demands-resources model: Challenges for future research. SA Journal of Industrial Psychology, 37(2), 1-9.

Demerouti, E., Bakker, A. B., Nachreiner, F., \& Schaufeli, W. B. (2001). The job demands-resources model of burnout. Journal of Applied Psychology, 86(3), 499.

Dicke, T., Stebner, F., Linninger, C., Kunter, M., \& Leutner, D. (2018). A longitudinal study of teachers' occupational well-being: Applying the job demands-resources model. Journal of Occupational Health Psychology, 23(2), 262.

Gajendran, R. S., \& Harrison, D. A. (2007). The good, the bad, and the unknown about telecommuting: meta-analysis of psychological mediators and individual consequences. Journal of Applied Psychology, 92(6), 1524-1541. 
Gambrell, D. (2020, April 4). How Covid-19 affects the U.S. workforce, by income and industry. Bloomberg. Retrieved from: https://www.bloomberg.com/news/features/2020-03-13/ how-coronavirus-affects-u-s-workforce-by-income-and-industry

Gao, Y., Shi, J., Niu, Q., \& Wang, L. (2013). Work-family conflict and job satisfaction: Emotional intelligence as a moderator. Stress and Health, 29(3), 222-228.

Gartner. (2020). Gartner HR survey reveals $41 \%$ of employees likely to work remotely at least some of the time post coronavirus pandemic. Newsroom. Retrieved from https://www.gartner.com/en/ newsroom/press-releases/2020-04-14-gartner-hr-survey-reveals41--of-employeeslikely-to-

Ghanayem, M., Srulovici, E., \& Zlotnick, C. (2020). Occupational strain and job satisfaction: The job demand-resource moderation-mediation model in haemodialysis units. Journal of Nursing Management, 28(3), 664-672.

Golden, T. (2007). Co-workers who telework and the impact on those in the office: Understanding the implications of virtual work for co-worker satisfaction and turnover intentions. Human Relations, 60(11), 1641-1667.

Golden, T. D., Veiga, J. F., \& Dino, R. N. (2008). The impact of professional isolation on teleworker job performance and turnover intentions: Does time spent teleworking, interacting face-toface, or having access to communication-enhancing technology matter? Journal of Applied Psychology, 93(6), 1412.

Groen, B. A., Van Triest, S. P., Coers, M., \& Wtenweerde, N. (2018). Managing flexible work arrangements: Teleworking and output controls. European Management Journal, 36(6), 727-735.

Hackman, J. R., \& Oldham, G. R. (1980). Work Redesign. Addison- Wesley.

Hair, J. F., Black, W. C., Babin, B. J., \& Anderson, R. E. (2013). Multivariate data analysis: Pearson new international edition. Pearson.

Hakanen, J. J., Bakker, A. B., \& Demerouti, E. (2005). How dentists cope with their job demands and stay engaged: The moderating role of job resources. European Journal of Oral Sciences, 113(6), 479-487.

Hakanen, J. J., Bakker, A. B., \& Schaufeli, W. B. (2006). Burnout and work engagement among teachers. Journal of School Psychology, 43(6), 495-513.

Han, J., Yin, H., Wang, J., \& Zhang, J. (2020). Job demands and resources as antecedents of university teachers' exhaustion, engagement and job satisfaction. Educational Psychology, 40(3), 318-335.

Handy, S. L., \& Mokhtarian, P. L. (1996). The future of telecommuting. Futures, 28(3), 227-240.

Hertel, G., \& Zacher, H. (2018). Managing the aging workforce. The SAGE handbook of industrial, work and organization psychology, 3, 396-428.

Herzberg, F. (1966). Work and the nature of man. Holland.

Hobfoll, S. E. (2001). The influence of culture, community, and the nested-self in the stress process: Advancing conservation of resources theory. Applied Psychology, 50(3), 337-421.

Hobfoll, S. E., Shirom, A., \& Golembiewski, R. (2000). Conservation of resources theory. Handbook of Rganizational Behavior, 57-81.

Hook, A., Sovacool, B. K., \& Sorrell, S. (2020). A systematic review of the energy and climate impacts of teleworking. Environmental Research Letters, 15(9), 093003.

Hoppock R. (1935). Job satisfaction. New York: Harper and Brothers. Reprint. : Amo Press, 1977.

Hu, L. T., \& Bentler, P. M. (1999). Cutoff criteria for fit indexes in covariance structure analysis: Conventional criteria versus new alternatives. Structural Equation Modeling: A Multidisciplinary Journal, 6(1), 1-55.

Huang, Q., Xing, Y., \& Gamble, J. (2019). Job demands-resources: A gender perspective on employee well-being and resilience in retail stores in China. The International Journal of Human Resource Management, 30(8), 1323-1341.

Kanekar, A., \& Sharma, M. (2020). COVID-19 and mental well-being: Guidance on the application of behavioral and positive well-being strategies. Health Care, 8(3), 336-342.

Karasek, R. A. (1979). Job demands, decision latitude, and mental strain: Implications for job redesign. Administrative Science Quarterly, 24, 285-308.

Kelly, M. M. (1985). Next workplace revolution: Telecommuting. Supervisory Management, 30(10), 2-7.

King, R. (2008). Telework : A critical component of your total rewards strategy. WorldatWork Press.

Kniffin, K. M., Narayanan, J., Anseel, F., Antonakis, J., Ashford, S. P., Bakker, A. B., et al. (2021a). COVID-19 and the workplace: Implications, issues, and insights for future research and action. American Psychologist, 76(1), 63.

Kniffin, K. M., Narayanan, J., \& Van Vugt, M. (2021b). COVID-19 is a moderating variable with its own moderating factors. Industrial and Organizational Psychology, 14(1-2), 149-151.

Knight, C., Patterson, M., \& Dawson, J. (2017). Building work engagement: A systematic review and meta-analysis investigating the effectiveness of work engagement interventions. Journal of Organizational Behavior, 38(6), 792-812.

Kumar, A., \& Nayar, K. R. (2020). COVID 19 and its mental health consequences. Journal of Mental Health, 1-2.

Lesener, T., Gusy, B., \& Wolter, C. (2019). The job demands-resources model: A meta-analytic review of longitudinal studies. Work \& Stress, 33(1), 76-103.

Lewig, K. A., Xanthopoulou, D., Bakker, A. B., Dollard, M. F., \& Metzer, J. C. (2007). Burnout and connectedness among Australian volunteers: A test of the job demands-resources model. Journal of Vocational Behavior, 71(3), 429-445.

Lu, M. H., Luo, J., Chen, W., \& Wang, M. C. (2019). The influence of job satisfaction on the relationship between professional identity and burnout: A study of student teachers in Western China. Current Psychology, 1-9.

Mansfield, R. (2018). Employee job satisfaction and attitudes in virtual workplaces. [Doctoral dissertation, Walden University].

Martin, B. H., \& MacDonnell, R. (2012). Is telework effective for organizations? Management Research Review, 35, 602-616.

Mayende, T. S., \& Musenze, I. A. (2018). Ethical leadership and staff retention: The moderating role of job resources in Uganda's healthcare sector. SA Journal of Industrial Psychology, 1-10.

Meijman, T. F., Mulder, G., Drenth, P., \& Thierry, H. (1998). Psychological aspects of workload. Handbook of work and organizational psychology, 1998, 2.

Miao, C., Humphrey, R. H., \& Qian, S. (2017). A meta-analysis of emotional intelligence effects on job satisfaction mediated by job resources, and a test of moderators. Personality and Individual Differences, 116, 281-288.

Moench, M. (2020). The coronavirus threatens older workers. Some are crucial to keeping the bay area running. The San Francisco Chronicle. Retrieved from https://www.sfchronicle.com/business/ article/The-coronavirus-threatens-older-workers-Someare-15130 735.php

Mueller, R. O., \& Hancock, G. R. (2001). Factor analysis and latent structure, confirmatory. International Encyclopedia of the Social \& Behavioral Sciences, 5239-5244.

Nilles, J. M. (1976). Telecommunications-transportation tradeoff: Options for tomorrow. John Wiley \& Sons, Inc.

Pliskin, N. (1998). Explaining the paradox of telecommuting. Business Horizons, 41(2), 73-78.

Pyöriä, P. (2011). Managing telework: Risks, fears and rules. Management Research Review, 34(4), 86-99.

Robbins, S. P., \& Judge, T. A. (2013). Organizational behavior. Pearson Education. 
Rudolph, C. W., \& Zacher, H. (2020). "The COVID-19 generation": A cautionary note. Work, Aging and Retirement, 6(3), 139-145.

Scanlan, J. N., \& Still, M. (2019). Relationships between burnout, turnover intention, job satisfaction, job demands and job resources for mental health personnel in an Australian mental health service. BMC Health Services Research, 19(1), 1-11.

Scheibe, S., Stamov-Roßnagel, C., \& Zacher, H. (2015). Links between emotional job demands and occupational well-being: Age differences depend on type of demand. Work, Aging and Retirement, 1(3), 254-265.

Skaalvik, E. M., \& Skaalvik, S. (2017). Still motivated to teach? A study of school context variables, stress and job satisfaction among teachers in senior high school. Social Psychology of Education, 20(1), 15-37.

Spector, P. E. (1997). Job satisfaction: Application, assessment, causes and consequences. Sage Publications.

Sun, M., Du, J., \& Xu, J. (2020). Math homework purpose scale for preadolescents: A psychometric evaluation. Current Psychology, 39(5), 1740-1748.

Tabachnick, B. G., Fidell, L. S., \& Ullman, J. B. (2007). Using multivariate statistics. Pearson.

Tavares, F., Santos, E., Diogo, A., \& Ratten, V. (2020). Teleworking in portuguese communities during the COVID-19 pandemic. Journal of Enterprising Communities: People and Places in the Global Economy, 1-16.

Tokarchuk, O., Gabriele, R., \& Neglia, G. (2021). Teleworking during the Covid-19 crisis in Italy: Evidence and tentative interpretations. Sustainability, 13(4), 2147.

Toropova, A., Myrberg, E., \& Johansson, S. (2021). Teacher job satisfaction: The importance of school working conditions and teacher characteristics. Educational Review, 73(1), 71-97.

Torten, R., Reaiche, C., \& Caraballo, E. L. (2016). Teleworking in the new milleneum. The Journal of Developing Areas, 50(5), 317-326.

Turetken, O., Jain, A., Quesenberry, B., \& Ngwenyama, O. (2010). An empirical investigation of the impact of individual and work characteristics on telecommuting success. IEEE Transactions on Professional Communication, 54(1), 56-67.

Unger, S., \& Meiran, W. R. (2020). Student attitudes towards online education during the COVID-19 viral outbreak of 2020: Distance learning in a time of social distance. International Journal of Technology in Education and Science, 4(4), 256-266.

Wang, W., Fu, Y., Qiu, H., Moore, J. H., \& Wang, Z. (2017). Corporate social responsibility and employee outcomes: A moderated mediation model of organizational identification and moral identity. Frontiers in Psychology, 8, 1906.

Weiss, H. M. (2002). Deconstructing job satisfaction: Separating evaluations, beliefs and affective experiences. Human Resource Management Review, 12(2), 173-194.

Xanthopoulou, D., Bakker, A. B., Dollard, M. F., Demerouti, E., Schaufeli, W. B., Taris, T. W., \& Schreurs, P. J. (2007). When do job demands particularly predict burnout? The moderating role of job resources. Journal of Managerial Psychology, 22(8), 766-786.

Yom, Y. H. (2013). Analysis of burnout and job satisfaction among nurses based on the job demand-resource model. Journal of Korean Academy of Nursing, 43(1).

Yulita, Y., Idris, M. A., \& Dollard, M. F. (2020). Effect of psychosocial safety climate on psychological distress via job resources, work engagement and workaholism: A multilevel longitudinal study. International Journal of Occupational Safety and Ergonomics, $1-18$.

Zeijen, M. E., Brenninkmeijer, V., Peeters, M. C., \& Mastenbroek, N. J. (2021). Exploring the role of personal demands in the healthimpairment process of the job demands-resources model: A study among master students. International Journal of Environmental Research and Public Health, 18(2), 632.

Publisher's note Springer Nature remains neutral with regard to jurisdictional claims in published maps and institutional affiliations. 